\title{
Social Capital as Dehumanizing Terminology
}

\author{
Robert J. Taormina, Angus C. H. Kuok, Wei Wei \\ Psychology Department, Faculty of Social Sciences and Humanities, \\ University of Macau, Macau (SAR), China \\ Email: Taormina@umac.mo
}

Received March 26 ${ }^{\text {th }}$, 2012; revised April 25 ${ }^{\text {th }}$, 2012; accepted May $9^{\text {th }}, 2012$

\begin{abstract}
This paper argues that the term "social capital" is an inappropriate terminology that is unsuited for theory or scientific empirical research. The arguments challenge the metaphor and definition by revealing the phrase to be dehumanizing, oxymoronic, anachronistic, and demeaning, which makes it incorrect, and even immoral, for proper use. It is also argued that the term is 1984-ish vis-à-vis Doublethink and Newspeak. It is recommended that the metaphors for "social capital" and its related term, "human capital," should be dropped from use. It is further recommended, for the purpose of increased clarity for theory building and for empirical research, and to avoid using dehumanizing terminology, that it is more appropriate to retain the term "social networking" as the general name for the process; such that, when attempting to measure related social networking concepts, researchers should specify operationally defined variable names that are more suited to proper scientific measurement of the research domains. For example, if "friends" are studied as helpers in a social network, that term may be used as a variable name, but under no circumstances should one's friends, or other people, be referred to or regarded as "capital."
\end{abstract}

Keywords: Social Capital; Terminology; Dehumanizing; Critique; Oxymoron; Anachronism

\section{Social Capital as Dehumanizing Terminology}

An analysis of the term "social capital" reveals it to be conceptually inappropriate, which makes it problematic for both theory building and research. To permit meaningful empirical testing, as Marx and Hillix (1973) explained, theories should follow certain rules that allow them to be tested and verified. One rule is that theories require an explication of their terms (i.e., they need to be operationalized) in order to have clear and meaningful definitions to make it possible to measure them. The need for clear, measurable terms is necessary for the next aspect of theory testing, i.e., to examine hypothesized (theorized) relationships among the variables that are relevant to the theory. Marx and Hillix (1973) explained that terms can be "primitive" (e.g., can be pointed to) or defined via semantic relationships (e.g., in pure theory). Unfortunately, the term "social capital" has had problems with its operationalization (see Thompson, 2009). The term also has inherent contradictions, which make it vague and ambiguous, such that the phrase "social capital" should be avoided, and should be replaced with more accurate terminology.

The term "social capital," as originally conceived, referred to social networking (interaction) among individuals and families, namely, for good will, fellowship, and sympathy among people (Hanifan, 1916); but the inclusion of the term "capital” to refer to this has led to serious problems with the concept. Therefore, it must be stated at the outset that no objections are being made to the idea that the practice of social networking could provide considerable benefits to the people and/or groups that engage in those activities. What is objectionable is the term "social capital” itself, which has inherent conceptual problems; and also objectionable is how this term is being misused in the literature.

Previous authors have pointed out difficulties with the term “social capital.” Recently, for example, Thompson (2009) iden- tified problems with the term, particularly the difficulty with using the phrase as a metaphor for seeking social cooperation, which contradicts the usual connotation of capital, which, in turn, relates to competitiveness. She demonstrates this by citing Coleman's (1988) explanation of "social capital," and pointing out that his use of the term is "undoubtedly an exploitative view of human relationships” (Thompson, 2009: p. 149). While Thompson's argument is accurate and well elaborated, there are further problems, such that some additional difficulties with the term need to be elucidated. This will be done in this paper by identifying its source by means of a brief history of the term, showing how the two-word phrase is an oxymoron, by demonstrating that the term is anachronistic (and politically) incorrect, and, thereby, explaining why it is not appropriate for writers to continue using the term.

\section{A Brief History of the Term "Social Capital”}

Although the actual origin and use of the phrase "social capital” might never be uncovered, its first printed appearance was by L. J. Hanifan (1916). Interestingly, even Hanifan was concerned about misunderstanding of the phrase because he explained that he was not using the term in a materialistic sense (e.g., of real estate, property, or cash), but, rather, was referring to fellowship and social interaction used by individuals, families, and groups, with the objectives of obtaining help for the individual and of building goodwill to improve living conditions for everyone in the community. This, which is what Hanifan intended, is a laudable and perfectly supportable idea, but Hanifan's need to warn his readers about the term makes it clear that, from the very beginning of the use of this term, the phrase has been (and remains) problematic.

The problem with placing the word "capital" in this phrase may be understood by tracing it back to the social philosopher 
and political economist, Adam Smith (1723-1790), whose (1776) book, The Wealth of Nations (An Inquiry into the Nature and Causes of the Wealth of Nations), identified major categories of wealth, particularly, land, labor, and capital. All of these types of wealth take various forms. Land, for example, can be farm land used for any kind of agriculture, which, in turn, can produce wealth. Labor, according to Smith, is the effort that one makes to produce something that other people want and, thus, can be sold, which also produces wealth. The term "capital" referred to personal property and money, both of which also take various forms. While money can be in cash or stocks, it is capital as personal property that particularly raises problems with the use of the term "social capital."

Personal property is usually (today) conceived as any material thing that one owns or possesses, such as clothes, automobiles, computers, etc. But in the 1700s, the time Adam Smith was writing, slaves were considered the personal property of the individual who owned those human beings that were held as slaves. This was because slavery had always existed in human history, and for centuries, particularly from the 16th to the 19th Centuries, the trade in slaves between Africa and North and South America was a very profitable business (see, e.g., Andrews \& Fenton 2001). The slave traders made a great deal of money by capturing and kidnapping people, transporting them to distant locations where they could be sold, and selling them to wealthy individuals such as land owners; and the land owners who bought the slaves then had relatively free labor (apart from the expense of feeding the slaves) to work their lands for the production of agricultural products that were sold for profit. The more slaves an individual owned the more land that could be worked, and the more profit that could be made. Hence, the more slaves one possessed, the wealthier that person was considered to be.

Thus, since "capital” refers to objects that are merely forms of materialistic wealth, it is certain that Hanifan (1916) was, as he said, using the term "social capital" in a figurative sense, i.e., metaphorically only (namely, as a linguistic device to stress the ideas presented in his thesis). Unfortunately, the term he introduced has been used indiscriminately by subsequent writers, and, sadly, is increasingly being used by today's writers as if the two terms represent no contradiction in ideas. The brief history given above, however, clearly indicates that the joining of the two terms, i.e., of "social" and "capital," has been problematic since its inception. Hence, the term is actually an oxymoron (an idea that is explained in a later section of this paper).

\section{Problems with, and Previous Critiques on, the Use of the Term "Social Capital"}

Beginning with Hanifan's (1916) introduction of the phrase "social capital" into the literature, which initiated conceptual and theoretical problems with the term, there have been additional problems that have taken various forms. The first and most obvious problem is with the definition. Some authors have already mentioned this weakness, as explained in an extensive discussion by Quibria (2003), who traced the problem to an early characterization of the term, i.e., "Coleman's [1988] work has opened up the way for a whole plethora of new definitions that often emphasize different and contradictory aspects of social capital” (p. 23).

Two more difficulties are directly related to the definitional problem with the phrase, i.e., the vagueness of the concept, and the trouble with measuring it. In reference to the term, Markusen (1999) suggested it was a "fuzzy concept," especially in industrial and regional studies. Durlauf (1999) was more precise in saying the term led to "conceptual ambiguity," which he related to the definitional problem. A further, more elaborate discussion of the vagueness of the term was offered by Smith and Kulynych (2002), who stated that "social capital brings together contradictory ideas, ignores the history and context of those ideas, and makes evaluative or normative theorizing difficult" (p. 152). The other problem, namely, measuring the concept, has also been discussed by previous writers. Durlauf (2002), for example, thought the concept was poorly measured, and Quibria (2003) stated that "the concept has remained largely amorphous and lacks the clarity and precision required to be used for rigorous empirical work" (p. 34).

One reason the term lacks precision is because some authors, following Bourdieu (1986) and Coleman (1988) who stressed the capitalistic aspects of the term, tried to extend the metaphor to larger entities (i.e., to a higher level of analysis than the individual). For example, some writers tried to apply social and/or human capital to the economic gains of organizations (Brooks \& Nafukho 2006), or to entire nations (Fukuyama 1995).

Thus, the term "social capital" has become a "catch-all" phrase because so many writers wish to apply the term to their different fields. In business studies in particular, the attempt to use this concept presented (albeit inappropriately) yet another opportunity to assess capitalistic (economic and/or financial) gain. This motivated an inordinate number of papers to use the term, as evidenced by over 15,000 articles (found in a search of the ABI/INFORM business database) that used "social capital" in their abstracts. As one example of the inappropriateness of using the term, one social networking study used the term "capital" to refer to measures such as interpersonal trust, voting (in elections), and attending religious services (Iyer, Kitson, \& Toh, 2005). Similarly, another study that tried to measure (human) "capital" did so with one test of "personality" and another of "cognitive ability," i.e., basic math skills (Ployhart, Van Iddekinge, \& Mackenzie, 2011). In other words, business writers today find the label of "social capital" to be so exciting that they attempt to use any number of variables to try to measure it, which only serves to further confound the concept.

Such approaches are problematic in three ways. First, stressing the materialistic aspects of the concept contradicts the original humanitarian intent (as Hanifan, 1916, noted). Second, broadening the concept without limits on what it was intended to be contributes to making the term even vaguer. That is, when more and more applications are attached to a single concept, the original meaning of the concept becomes increasingly obscure.

The third way in which expanding an idea to additional realms of study creates problems for defining a concept is by exponentially increasing the number of variables that might be used to represent what "social capital" is supposed to be. This does not mean that the concept of social networking cannot be studied in other research disciplines. But when researchers in different fields try to measure a term that is ambiguous because of its metaphorical label, the idea loses its meaning. That is, each field of study already has numerous field-relevant variables (which may be numbered in the hundreds), and when a concept is projected to a different field of study, the variables that already exist and that had been previously labeled, defined, and researched in that field come to be regarded as elements of the concept that is being projected onto that field. This confuses 
not only the original concept, but confounds the variables in the other fields of study. Thus, adding variables to represent and assess a concept that is already vague tends to create more confusion for the concept; as Quibria (2003: p. 25, footnote) noted (citing Fischer, 2001) "the concept is expanding in all directions like a swamp in bad weather."

Adding to the problems with the term "social capital" is that it has become a research "fad," i.e., a popular concept to study. To understand this, consider how the popularity of this inappropriate terminology parallels the introduction of a new, brandname product, such as "designer jeans." Everyone wants to wear them, so they are worn indiscriminately, even though they do not fit! Brand-name products are bought by many people mainly because those products are popular and "in fashion." Thus, just as people think that wearing designer jeans will get them noticed, even though the clothes often do not fit; in a similar way, it seems that researchers today believe that if they also use the term "social capital" it will increase the chances of their papers being published, even if the concepts do not fit. Consequently, the various problems with the term proliferate in proportion to its popularity and increased use.

In response to these difficulties, some writers have acknowledged the definitional problem and attempted to redefine the term, but did not try to rename it. That approach, however, is inadequate (and futile) because retaining the terminologywhile only changing the definition-does not solve the inherent oxymoronic nature of the metaphoric phrase (see below). Other, more insightful writers have concluded that the term is so problematic that it should be dropped from usage (Bowles \& Gintis, 2002), or that both the metaphor and the term should be completely abandoned (Arrow, 2000).

\section{The Term "Social Capital” as an Oxymoron}

An oxymoron is a phrase that combines opposite terms, i.e., "a pair of opposed or markedly contradictory terms" (Oxford English Dictionary n.d.)," which, in rhetoric, is often used to emphasize a contradiction. The way it is being used in the literature today, however, is apparently only to link two words that are taken at face value for their common usage (not for their rhetorical effect), and without concern for their inherent contradiction. Yet, when the phrase "social capital" is examined in regard to the actual meaning of its two elemental terms, its oxymoronic nature readily becomes apparent. The first term, "social," is an adjective that refers to groups of people, i.e., "consisting or composed of people associated together for friendly interaction or companionship" (Oxford English Dictionary n.d.).

The word "social" is widely used with the idea of involving interpersonal interaction. Sociological theory has suggested that people react to things according to the meanings those things have for them, and emphasized that "the meanings of such things is derived from, or arises out of, the social interaction that one has with one's fellows" (Blumer, 1969: p. 2). Also, according to the Oxford English Dictionary (n.d.), "social” relates to activities in which people meet each other for pleasure in times of leisure. It also means living together in groups, and involves interactions between two or more individuals. In addition, the noun form of "social" means a gathering of people, including ones organized by the members of a particular club or group. Essentially, then, the term "social" refers to interactions among people, especially in groups, and often with the aim of having pleasure or enjoyment.
The term "capital," on the other hand, is widely used in business and economics to refer to money and property, especially cash and other assets, which include inventory, supplies, equipment, land, buildings, and stocks, etc., that a person or a business possesses (see The Legal Dictionary, n.d.). It should be noted that all the examples referred to in the definition are material things, vis-à-vis immaterial things (e.g., emotions) that are involved in social interactions. Furthermore, Thompson (2009) explained that the word "capital” conveys a sense of competitiveness, such that "it involves rivalries, taking advantage of weaknesses, and being threatened by one's fellows in the business, it is the antithesis of social cohesion" (p. 148) and that this is antithetical to the meaning of the term "social."

Therefore, the term "social capital" is actually an oxymoron because it joins the concept of engaging in "social" interactions, i.e., people coming together for pleasurable purposes (not necessarily for materialistic ends), with the word "capital,” which refers to people competing with each other for the explicit purpose of gaining money or some other material advantage over others. More critically, use of the term "capital” for this purpose, and especially when the intended meaning of the term "social capital" is for "using" other people to increase one's own self gain, verges on reducing people to mere "tools," just as slaves were used by their masters for the purpose of gaining economic benefits for the masters, and then the slaves were put aside or discarded once they had served the master's purpose.

\section{The Term "Social Capital” as an Anachronism}

It should be remembered that the idea of "capital," as it is used today, evolved from the work by Adam Smith, who lived in the 18th Century, when slavery was regularly practiced in many parts of the world (the USA did not abolish slavery until 1865). To economists of the 18th Century, slavery was a form of capital, and slave owners could measure their wealth in terms of the number of slaves they owned; just as people in agrarian societies measure wealth in terms of the number of cattle they own (Doran, Low, \& Kemp, 1979).

Furthermore, it should also be realized that the phrase "social capital" originated in 1916, when slavery still existed in many countries of the world (see Miers, 2003). If it seems excessive to link the idea of slavery to the term "social capital," one merely needs to understand that when the concept is used for the purpose of competitive financial advantage, as Coleman (1988) and some other authors applied it; then it can readily be seen that the actor is "using" other people, which reduces those other people to mere "tools," and thereby dehumanizes them.

If the slavery comparison seems to be an extreme idea there is yet another, related reason that the term is anachronistic, namely, self-gain at the cost of other people. Specifically, in the Coleman (1988) sense of using others for the intent of gaining advantages over other people, the "using" of people is an anachronistic idea. That is, in the past, the exploitation of other people was not only common practice, but, according to Karl Marx (1867), was characteristic of capitalism, which he attacked for this reason. In more recent times (even though capitalism is still the world's principal economic system), the exploitation of workers, and of people in general, is regarded as unethical (Mayer, 1988), immoral, and unacceptable to the point that governments and other groups attempt to eradicate it (Pines \& Meyer, 2005).

Thus, slavery and the exploitation of other people are beha- 
viors that belong to the past. Today, especially in light of the French Revolution (ca. 1790s) that declared the importance of liberty, equality, and fraternity (liberté, égalité, fraternité), and since the Civil Rights Movement in the USA (ca. 1960s), people expect to have equality in their rights and in how they should be treated. Therefore, if the use of the term "social" is humanistic, as Hanifan (1916) intended it to be, then a phrase that links the concept of humanism together with the word "capital," which reifies the inhumane treatment of human beings, must be regarded as anachronistic since the exploitation of other people is inappropriate in modern societies. Furthermore, since it is an oxymoron and an anachronism, the term "social capital” is not only linguistically inappropriate or incorrect, but it is also "politically incorrect" as well as immoral.

\section{The Term "Social Capital" as a "Politically Incorrect” and Immoral Term}

To be "politically correct" refers to the use of language, ideas, policies, and behaviors that avoid social offense to people's personal characteristics, such as age, culture, disabilities, gender, race, and sexual orientation, or their beliefs, e.g., religion. Although the term "politically correct" also has been misused (e.g., among comedians), the definition provided here represents the original intention, i.e., of avoiding insults to people. If this term "politically correct" is confusing to the reader (because of the way it has been distorted by inappropriate use in the past), a clearer word may be substituted, that is, "morality." Thus, it is politically incorrect, or immoral, to use words that (intentionally or even unintentionally) give offense to, insult, or demean people.

As demonstrated earlier, the phrase "social capital" was shown to be an oxymoron because part of the term proffers the idea that other people can be treated as someone's personal asset, and the term was also revealed to be anachronistic. Thus, based on the above definition of what is politically correct, use of the term "social capital" is politically incorrect, or at least morally wrong, because it advocates the idea that human beings are "capital," i.e., something to be used as a tool (or slave) in order for the actor to achieve some personal gain, and that people can be discarded when their usefulness has expired.

This utilitarian conception of "social capital" is explicit in the way it is used by many writers today, particularly in the business and management literature. As Bourdieu's (1986) sociological conception of the term was about utilizing social connections for personal advantage, which is already utilitarian, the business and management use of the term takes this approach to the extreme. That is, those authors are virtually ignoring the benefits that making a social network can have for the individual, and instead stress the idea that certain characteristics of a company's employees can result in financial advantages for the organization. Sadly, the most obvious implication is that management can use, or exploit, employees primarily for the purpose of making a profit for the organization.

That utilitarian approach to management encourages the practice of considering workers to be exchangeable parts that can be "bought and sold" (very much like slaves) and employed (used) for as long as they are valuable (i.e., as long as their work provides profit to the organization), and then fired (discarded) when the business owners think a worker's usefulness (value) has expired. Thus, the wide use of the term "social capital" in business and economics is extremely demeaning to the human race because it is actually (albeit implicitly) about a form of human exploitation. In other words, use the term and the concept, ipso facto, advocates human mistreatment. This is a repulsive concept (and practice) because it dehumanizes people, and, thus, is the epitome of being not only politically incorrect, but of being immoral.

\section{The Term "Social Capital" as "Doublethink" and "Newspeak"}

Beyond the several problems with the term already described in the foregoing sections, the phrase "social capital" is also strongly reminiscent of George Orwell's (1949) book, Nineteen Eighty-Four, for two reasons. First, the book portrays a man (Winston Smith) who wants to maintain his humanness in an environment that is designed to eliminate humanity. That is, since the term "social" refers to humans and/or their qualities, when writers use the term "social capital" they are functioning in the same way that "Big Brother" did in Orwell's book. More specifically, Big Brother dehumanized and reduced the person to an emotionless cog in a machine (the organization) that performs work for the master (Big Brother; society); just as slaves (capital) were treated as inhuman with their primary purpose being only to perform work and create wealth for their masters and for the masters' society.

The second reason that "social capital" is reminiscent of Nineteen Eighty-Four is that the two words in the phrase promote a kind of "Doublethink." That is, since the two words are contradictory in their original meanings, as noted by Thompson (2009), the phrase requires us to simultaneously hold two opposing ideas in mind, and to believe in them both! Perpetuating such Doublethink is also reminiscent of "Newspeak," which is a term that reflected Orwell's anguish regarding (governments or societies) using language to control people's minds. For example, in order to eliminate the word "bad" from the language (because it had a negative connotation, which the controllers would consider a dangerous state of mind for workers to have because they might view their controllers negatively), Big Brother created the word "ungood" to replace it.

By comparison to the Orwellian concepts, the emphasis on the dehumanizing "capital” aspect of the phrase "social capital” works to reverse the "social" concept that was originally employed to portray humanistic characteristics. Thus, use of the phrase "social capital" works to eliminate the more humane facet of the concept as if it were unnecessary, which could lead to a reduction in both having thoughts about and being aware of our humanity.

\section{Recommend Renaming of the Terms "Social Capital" and "Human Capital"}

It is clear from the foregoing analyses that the term "social capital" is very problematic. Although this paper did not address the many difficulties with a related phrase, "human capital," these two terms are closely linked and both present problems, not only in their vague, awkward, and inappropriate definitions, but also with trying to measure the intended concepts. Since the terms are so problematic, researchers must consider what to do about them. Should the terms be redefined, abandoned, or replaced?

As noted previously, there have already been several authors who complained that the term "social capital" is vague and 
difficult to measure. Unfortunately, some writers have only suggested redefining the term, which is the equivalent of "putting new wine into old bottles.” Only a few, more insightful, authors (Arrow, 2000; Bowles \& Gintis, 2002) have seen the need to abandon the term. But because of the popularity of the ideas underlying the concepts, it is unlikely that the terms will be immediately and unanimously discarded. Therefore, the best solution would be for researchers to: 1) desist from using the metaphors, and 2) replace those phrases with terms that are operationally grounded and more appropriate to theory building.

For the term "social capital," first consider that it was originally used to represent the common practice of a person or group of persons interacting with other human beings in order to help them either individually or together to overcome problems or improve their living situation. Thus, what they are actually doing is social networking. Social networking has existed for thousands of years in many societies (Taormina \& Gao, 2010), so it involves very real human behaviors. Additionally, there is already a broad literature on the topic of social networking, such that these behaviors have been and are still being studied on a regular basis. Furthermore, the term "social networking" refers to the same behaviors that are involved when the term "social capital" is used.

Consider also that social networking does not inherently suggest any capitalistic motives; it only refers to certain social behaviors, while the objectives of those networking behaviors could be for any purpose. Hence, the term "social networking" could avoid the problem of assuming that "social capital" should have financially advantageous outcomes, which is an assumption that has been challenged by authors who point out that "social capital" can have undesirable results (Smith \& Kulynych, 2002; Sobel, 2002). The term "social networking," on the other hand, is a more "neutral" term because it refers to a process and not an outcome; which means it could be for any purpose desired by the members performing the networking behaviors.

It is therefore recommended that both the term and the metaphor for "social capital" be abandoned, and that the term "social networking" be maintained as the overarching concept. In addition, it is further recommended that the objectives of social networking should be treated as separate variables from the networking behaviors, and that those objectives should be explicitly specified by the researcher as intended outcomes of social networking.

With regard to the term "human capital," Lehnen and McGregor (1994) defined it as "the human capacity for ... productivity” (p. 22). In other words, writers who use that term consider it to be the human abilities that enable people to perform work that produces economic value. Thus, the term "human capital" is even more repugnant than "social capital" because it reduces human skills and personality characteristics to mere currency to be used by others (e.g., managers) for financial gain. Hence, this term "human capital" should surely be abandoned.

\section{How to Assess the Concepts}

Regarding how to assess these concepts, the answer can readily be found in the type of variables that researchers have used when attempting to measure them, e.g., the "knowledge and skills built up throughout schooling, higher education, vocational training and work experiences" (Au, Altman, \& Roussel, 2008: p. 20). As another example, if "friends" are studied as helpers in one's social network, the term "friends" may be used as the variable name, but under no circumstances should one's friends be referred to or regarded as "capital." Furthermore, an overview of the research on this topic would reveal that the variables are usually selected from demographic descriptors, human knowledge, skills, abilities, and personality characteristics, all of which already exist as variables in the social science and management literatures.

Hence, consistently using existing variable names is necessary to foster clarity in both theory and research, and would also facilitate communication with researchers from related fields, such as social psychologists, who find it repulsive to use the word "capital" when referring to human beings and/or human characteristics. Indeed, psychologists have always endeavored, via operationalized definitions, to classify human variables more clearly and precisely within the domains of human personality, skills, and abilities, where they should be based. Therefore, researchers can avoid the dehumanizing terminology by simply using the appropriate labels that already exist for the variables they wish to measure in their research.

\section{Conclusion}

As can be seen in the many problems arising from use of the terms "social capital" and "human capital," which are selfcontradicting, ambiguous, anachronistic, and even immoral, the terms do not lend themselves to theory, which requires that terms must be rigorously precise to be usable in theory building and empirical research. This can be achieved in the following ways: First, by retaining the term "social networking" as the best name for the overarching concept (rather than trying to rename it with the phrase "social capital"); and, second, by abandoning the oxymoronic metaphors. In order to achieve the latter, it is strongly recommended that the terms "social capital" and "human capital" be discarded in preference for variable names from the existing literature that are more accurate labels, such as those that refer to human demographics and human personal characteristics. That is, there already exist operationally defined variables with clearer, more accurate terminology that is better suited to proper scientific measurement of the domains that theorists wish to describe and that researchers would like to assess. Therefore, by using more appropriate terminology to examine social networking concepts, theorists and researchers could avoid the use of demeaning language, and promote the advancement of more humane terminology in scientific research.

\section{REFERENCES}

Andrews, S. C., \& Fenton, J. P. (2001). Archaeology and the invisible man: The role of slavery in the production of wealth and social class in the Bluegrass Region of Kentucky, 1820 to 1870. World Archaeology, 33, 115-136. doi:10.1080/00438240126649

Arrow, K. J. (2000). Observations on social capital. In P. Dasgupta, \& I. Serageldin (Eds.), Social capital: A multifaceted perspective (pp. 35). Washington DC: World Bank.

Au, A. K. M., Altman, Y., \& Roussel, J. (2008). Employee training needs and perceived value of training in the Pearl River Delta of China. Journal of European Industrial Training, 32, 19-31. doi:10.1108/03090590810846548

Blumer, H. (1969). Symbolic interactionism. Englewood Cliffs, NJ: 


\section{R. J. TAORMINA ET AL.}

Prentice-Hall.

Brooks, K., \& Nafukho, F. M. (2006). Human resource development, social capital, emotional intelligence: Any link to productivity? Journal of European Industrial Training, 30, 117-128. doi:10.1108/03090590610651258

Bourdieu, P. (1986). The forms of capital. In J. Richardson (Ed.), Handbook of theory and research for the sociology of education (pp. 241-258). New York, NY: Greenwood.

Bowles, S., \& Gintis, H. (2002). "Social capital” and community governance. Economic Journal, 112, 419-436.

doi:10.1111/1468-0297.00077

Coleman, J. S. (1988). Social capital in the creation of human capital. American Journal of Sociology, 94, 95-120.

Doran, M. H., Low, A. R. C., \& Kemp, R. L. (1979). Cattle as a store of wealth in Swaziland: Implications for livestock development and overgrazing in Eastern and Southern Africa. American Journal of Agricultural Economics, 61, 41-47. doi:10.2307/1239498

Durlauf, S. N. (1999). The case "against” social capital. Focus, 20, 1-5.

Durlauf, S. N. (2002). On the empirics of social capital. Economic Journal, 112, 459-479. doi:10.1111/1468-0297.00079

Fischer, C. S. (2001). Bowling alone: What's the score? Paper presented at the meeting of the American Sociological Association (August 2001). Anaheim, CA.

Fukuyama, F. (1995). Trust: Social virtues and the creation of prosperity. London: Hamish Hamilton.

Hanifan, L. J. (1916). The rural school community center. Annals of the American Academy of Political and Social Science, 67, 130-138. doi:10.1177/000271621606700118

Iyer, S., Kitson, M., \& Toh, B. (2005). Social capital, economic growth, and regional development. Regional Studies, 39, 1015-1040. doi:10.1080/00343400500327943

Lehnen, R. G., \& McGregor, E. M. (1994). Human capital report cards for American states. Policy Sciences, 27, 19-35. doi:10.1007/BF00999597

Markusen, A. (1999). Fuzzy concepts, scanty evidence, policy distance: The case for rigor and policy relevance in critical regional studies. Regional Studies, 33, 869-884. doi:10.1080/00343409950075506

Marx, K. (1867). Das Kapital: Kritik der politischen Ökonomie. Ham- burg: Verlag von Otto Meisner.

Marx, M. H., \& Hillix, W. A. (1973). Systems and theories in psychology (2nd ed.). New York, NY: McGraw-Hill.

Mayer, J. (1988). Themes of responsibility: A survey of three professional schools. Journal of Business Ethics, 7, 313-320. doi:10.1007/BF00381837

Miers, S. (2003). Slavery in the twentieth century: The evolution of a global problem. Lanham, MD: AltaMira.

Orwell, G. (1949). Nineteen eighty-four. London: Secker \& Warburg.

Oxford English Dictionary. http://www.oed.com/view/Entry/135679

Oxford English Dictionary. http://www.oed.com/view/Entry/183739

Pines, G. L. S., \& Meyer, D. G. (2005). Stopping the exploitation of workers: An analysis of the effective application of consumer or socio-political pressure. Journal of Business Ethics, 59, 155-162. doi:10.1007/s10551-005-3410-3

Ployhart, R. E., Van Iddekinge, C. H., \& Mackenzie, W. I. (2011) Acquiring and developing human capital in service contexts: The interconnectedness of human capital resources. Academy of Management Journal, 54, 353-368. doi:10.5465/AMJ.2011.60263097

Quibria, M. G. (2003). The puzzle of social capital: A critical review. Asian Development Review, 20, 19-39.

Smith, A. (1776). An inquiry into the nature and causes of the wealth of nations. London: Strahan \& Cadell.

Smith, S. S., \& Kuylnych, J. (2002). It may be social, but why is it capital? The social construction of social capital and the politics of language. Politics \& Society, 30, 149-186. doi:10.1177/0032329202030001006

Sobel, J. (2002). Can we trust social capital? Journal of Economic Literature, 40, 139-154. doi:10.1257/0022051027001

Taormina, R. J., \& Gao, J. H. (2010). A research model for guanxi behavior: Antecedents, measures, and outcomes of Chinese social networking. Social Science Research, 39, 1195-1212. doi:10.1016/j.ssresearch.2010.07.003

The Legal Dictionary. http://legal-dictionary.thefreedictionary.com/capital

Thompson, D. (2009). What does "social capital" mean? Australian Journal of Social Issues, 44, 145-161. 